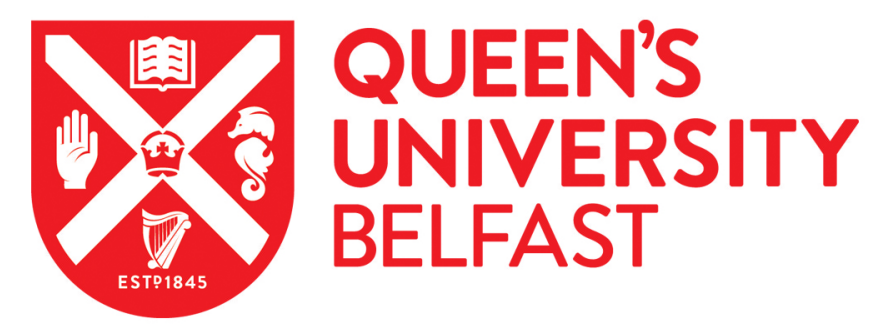

\title{
Investigation of spherical alumina supported catalyst for carbon nanotubes production from waste polyethylene
}

Liu, X., He, S., Han, Z., \& Wu, C. (2021). Investigation of spherical alumina supported catalyst for carbon nanotubes production from waste polyethylene. PROCESS SAFETY AND ENVIRONMENTAL PROTECTION, 146, 201-207. https://doi.org/10.1016/j.psep.2020.08.027

Published in:

PROCESS SAFETY AND ENVIRONMENTAL PROTECTION

Document Version:

Peer reviewed version

Queen's University Belfast - Research Portal:

Link to publication record in Queen's University Belfast Research Portal

Publisher rights

Copyright 2021 Elsevier.

This manuscript is distributed under a Creative Commons Attribution-NonCommercial-NoDerivs License

(https://creativecommons.org/licenses/by-nc-nd/4.0/), which permits distribution and reproduction for non-commercial purposes, provided the author and source are cited.

\section{General rights}

Copyright for the publications made accessible via the Queen's University Belfast Research Portal is retained by the author(s) and / or other copyright owners and it is a condition of accessing these publications that users recognise and abide by the legal requirements associated with these rights.

Take down policy

The Research Portal is Queen's institutional repository that provides access to Queen's research output. Every effort has been made to ensure that content in the Research Portal does not infringe any person's rights, or applicable UK laws. If you discover content in the Research Portal that you believe breaches copyright or violates any law, please contact openaccess@qub.ac.uk. 


\title{
Investigation of spherical alumina supported catalyst for carbon nanotubes production from waste polyethylene
}

\author{
Xiaotong $\mathrm{Liu}^{\mathrm{a}, \mathrm{b}}$, Su He $\mathrm{H}^{\mathrm{a}}$, Zhenan $\mathrm{Han}^{\mathrm{c}}$, Chunfei $\mathrm{Wu}^{\mathrm{a}}$ \\ ${ }^{a}$ School of Chemistry and Chemical Engineering, Queen's University Belfast, \\ Belfast, Northern Ireland, HU7 1NN \\ ${ }^{\mathrm{b}}$ School of Engineering and Computer Science, Faculty of Science and Engineering, \\ University of Hull, Hull, HU6 7RX \\ ${ }^{\mathrm{c}}$ Water and Environmental Protection Sector, China Construction Third Bureau \\ Group Co., Ltd. \#1241 Zhongshan Drive, Jiangan District, Wuhan, China 430014 \\ Corresponding authors: Tel: +44 (0) 2890975573, Email: c.wu@qub.ac.uk
}

\begin{abstract}
Thermo-chemical conversion of plastics provides an economic flexible and environmentally friendly method to recycle waste plastics, and generates valuable materials, such as carbon nanotubes (CNTs) and syngas. The development of catalysts is a key challenge for improving the quantity and quality of CNTs. In this study, spherical catalysts loaded with Ni were studied to control CNTs growth using waste plastic as the feedstock. Three parameters were studied, including catalytic temperature, $\mathrm{Ni}$ content and plastics/catalysts ratio. A fixed two-stage reactor was used for thermal pyrolysis of plastic waste and the materials were characterized with various methods including scanning electronic microscopy (SEM), temperature programme oxidation (TPO) and X-ray diffraction (XRD). The results showed that different contents of Ni loaded on sphere results in the formation of metal particles with various sizes, thus leading to CNTs production with different quantity and quality. In addition, an optimal catalytic temperature at $800{ }^{\circ} \mathrm{C}$ is suggested for CNTs formation with the $\mathrm{Ni} /$ sphere catalyst, as the catalyst might not be activated at $600{ }^{\circ} \mathrm{C}$ and $700{ }^{\circ} \mathrm{C}$.
\end{abstract}

Keywords: Plastics waste; Carbon nanotubes; sphere; Nickel; catalyst 


\section{Introduction}

Since carbon nanotubes (CNTs) were first introduced in detail by Iijima (Iijima, 1991; Radushkevich and Lukyanovich, 1952), it attracts much attention and interest. Carbon nanotubes are classified into single-walled nanotubes (SWNTs) and multi-walled nanotubes (MWNTs), according to different atomic structure (Li et al., 2004). This material has extraordinary properties, for example, high mechanical strength (100 times more than copper conductivity), good electrical and high thermal stability, and the related promising potential applications (Zhuo and Levendis, 2014). Various methods have been developed and studied for CNTs synthesis, such as laser ablation, arc discharge and chemical vapor deposition (Mishra et al., 2012). Chemical vapor deposition (CVD), due to its relatively low cost and capable of producing large amount of CNTs in short time, is currently the most widely used. This method used hydrocarbon gases as carbon sources and catalysts particles to nucleate the CNTs growth (Trojanowicz, 2006). Hydrocarbon gases come from thermal conversion of feedstock, including methane, ethylene, hydrogen and carbon monoxide. For example, six different hydrocarbons (methane, hexane, cyclohexane, benzene, naphthalene and anthracene) were studied as carbon precursors to produce CNTs over $\mathrm{Fe} / \mathrm{MgO}$ catalysts by Li et al. (Li et al., 2004). Methane was reported more chemically stable for SWNTs formation. Ago et al. investigated $\mathrm{CNTs}$ yield with $\mathrm{CH}_{4}$ as feedstock and Fe-Mo binary as catalysts (Ago et al., 2006). In addition, Lee et al. (Lee et al., 2003) studied the performance of catalysts for CNTs growth from mixed gases. Fe-based catalyst was found to be the most active one for CNTs growth under $\mathrm{CO} / \mathrm{NH}_{3}$ flow with a ratio of 18.

Alternative carbon sources derived from plastics waste (including polypropylene PP, polyethylene PE and so on) can also be used to reduce the cost of CNTs production and to manage the increasing amount of plastic wastes. This process have been recently studied. For example, Panahi et al. investigated the influence of different plastics (PE, PP PET, and PS) on produced CNTs. The results revealed that PP was the most productive plastic feedstock, which was contributed to the high carbon content and the 
ratio of hydrocarbons to other gases generated after pyrolysis at $800{ }^{\circ} \mathrm{C}$ (Panahi 2019). Hard plastics such as phenolic formaldehyde as carbon source was also be used for CNTs production by Gao et al. (Gou et al., 2020), as recently reported that using $\mathrm{Al}_{2} \mathrm{O}_{3}$ supported Ni and Fe catalyst yielded CNTs $\sim 24.07 \%$ and $34.39 \%$, respectively. Yao et al. (Yao and Wang, 2020) revealed that the CNTs growth from Ni-based catalyst through diffusion of carbon nucleated on the $\mathrm{Ni}$ surface rather than precipitation from nickel carbide $\left(\mathrm{Ni}_{3} \mathrm{C}\right)$. Acomb et al. (Acomb et al., 2015) evaluated the effect of feedstock to catalysts ratio and temperature on the CNTs production from plastics waste (low density polyethylene), an increase temperature and higher usage of plastic was reported to form higher yield of CNTs. Later on, $\mathrm{Ni}, \mathrm{Fe}, \mathrm{Co}$ and $\mathrm{Cu}$ on alumina supported catalysts were studied to produce CNTs from LDPE feedstock. Results showed that $\mathrm{Fe}$ and Ni catalysts produced the highest yield of CNTs owing to the proper strength of metal-support interactions (Acomb et al., 2016). Mishra et al. (Mishra et al., 2012) used waste polypropylene (PP) as precursor for synthesizing CNTs by CVD method in the presence of $\mathrm{Ni}$ based catalysts at three different temperatures $(600,700$, and $800^{\circ} \mathrm{C}$ ). The purest CNTs was formed at $800^{\circ} \mathrm{C}$. Therefore, Ni-based catalyst was proved to be a cost-effective catalyst with high catalytic performance in CNTs production from thermal-chemical conversion of plastics.

Catalyst support has been demonstrated to play a vital role in the determination of the catalytic performance on CNTs growth. Spherical alumina as an effective catalyst support have been used in various reactions, such as ethanol reforming (Fajardo and Probst, 2006), methanol reforming (Lindström et al., 2002), ethylene glycol reforming (Kiadehi and Taghizadeh, 2018). In CNTs synthesis, spherical alumina supported catalyst have been demonstrated to influence the orientation of CNTs growth (Dichiara and Bai, 2012; He et al., 2011, 2010) and the structures of grown CNTs (Han et al., 2004). However, the current researches have not yet revealed the influences of spherical structure alumina catalyst on CNTs synthesis using of plastics waste as carbon source. 
Here, in this research, $\mathrm{Ni} /$ sphere was used as catalysts to produce CNTs from plastics waste by CVD process. The mechanism of CNTs formation for this special structure catalysts, assisted with different parameters (temperatures and catalysts content) were investigated.

\section{Experimental}

\subsection{Materials preparation}

High density polyethylene plastics (HDPE) pellets with $2 \mathrm{~mm}$ diameter provided by Poli Plastics Pellets were consumed as feedstock in this study. Catalysts were prepared by impregnation method. Catalyst substrate used in this study was aluminium oxide sphere, which was purchased from Alladdin. The received sphere alumina catalyst was dried in oven at $100^{\circ} \mathrm{C}$ for 24 hours. Then the required amounts $\left(0.1\right.$ and $\left.1.0 \mathrm{~mol} \mathrm{~L}^{-1}\right)$ of Ni $\left(\mathrm{NO}_{3}\right)_{2} .6 \mathrm{H}_{2} \mathrm{O}$ were dissolved in water. The formed solution was dropped on the spheres until it saturated. The obtained wet Ni/sphere was dried in the oven at $100{ }^{\circ} \mathrm{C}$ for $24 \mathrm{hrs}$, then calcined in air at $750{ }^{\circ} \mathrm{C}$ with $2{ }^{\circ} \mathrm{C} \mathrm{min}^{-1}$ heating rate for 3 hours. It is noted that the $\mathrm{Ni} /$ sphere catalysts prepared from using 0.1 and $1.0 \mathrm{~mol} \mathrm{~L}^{-1} \mathrm{Ni}\left(\mathrm{NO}_{3}\right)_{2} .6 \mathrm{H}_{2} \mathrm{O}$ was assigned as $0.1 /$ sphere and $1.0 /$ sphere, respectively in this paper.

\subsection{CNTs synthesis from catalytic pyrolysis of plastics}

A two-stage catalytic thermal-chemical conversion reaction system (Figure 1.) consisting of a plastic pyrolysis stage and a catalytic gasification stage. In each experiment, about $1 \mathrm{~g} \mathrm{HDPE}$ was pyrolysed at around $500{ }^{\circ} \mathrm{C}$ at the first stage. Different reaction temperatures were used in the second stage $\left(600^{\circ} \mathrm{C}, 700^{\circ} \mathrm{C}\right.$, and $\left.800{ }^{\circ} \mathrm{C}\right) . \mathrm{N}_{2}$ was used as carrier gas with $100 \mathrm{ml} \mathrm{min}^{-1}$ flow rate. The total reaction time was 60 mins. The system was then slowly cooled down to the room temperature with continuous 100 $\mathrm{ml} \mathrm{min}^{-1} \mathrm{~N}_{2}$ gas. The spent $\mathrm{Ni} /$ sphere catalyst including the grown CNTs were collected for further characterizations. The optimum reaction parameters were studied in relative to their influences on the growth of CNTs. 


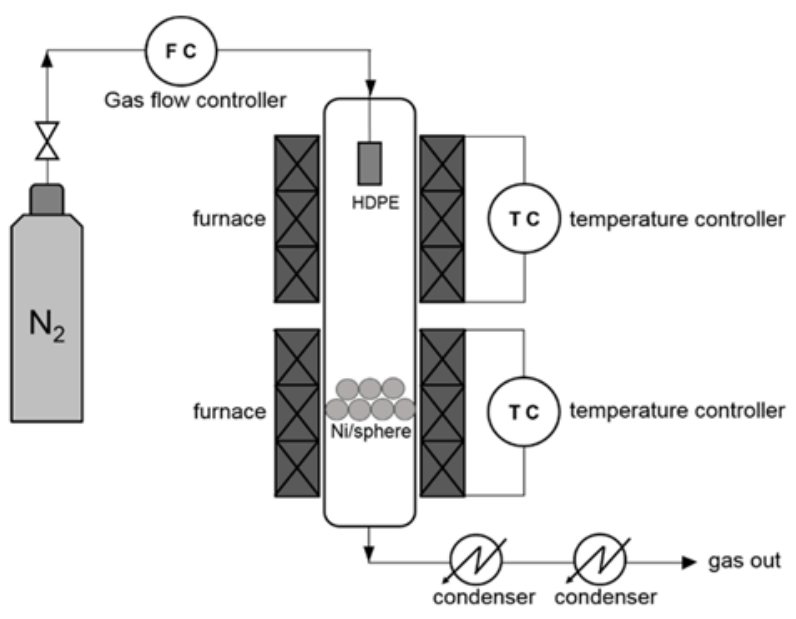

Figure 1. A schematic diagram of the reactor for the synthesis CNTs from waste plastics by $\mathrm{Ni} / \mathrm{sphere}$ catalysts

\subsection{Sample characterization}

A scanning electron microscope (SEM) Stereoscan 360 and a transmission electron microscope (TEM) JEOL 2010 were used to analyse the surface and the internal morphology of original aluminum oxide sphere. Energy dispersive spectroscope in TEM was to further identify the elements of sphere. Sample crystallinity was evaluated by powder X-ray diffraction (XRD), analyzed by Stoe IPDS2 software. CNTs formation on the $\mathrm{Ni} /$ sphere after catalytic pyrolysis reaction was also investigated by SEM and TEM. Distribution of CNTs diameters according to SEM results was carried out using Image-J software. Temperature programmed oxidation (TPO) of the spent $\mathrm{Ni} /$ sphere catalysts was analysed to obtain the information of carbon formation. The mechanism for CNTs formation on sphere catalysts at different reaction temperatures were carried out combining with SEM analysis.

\section{Results and discussion}

\subsection{Optimum reaction parameters investigation}

The reaction parameters CNTs formation from catalytic pyrolysis of plastics play important roles. Different parameters could influence the morphology, length and diameter of CNTs, the growth rate of CNTs and also reaction mechanism in the process 
(Dasgupta et al., 2011). Therefore, optimum parameters for particular catalyst need to be studied for particular catalysts to produce the optimum quality and quantity of CNTs. In this research, two reaction parameters using sphere catalysts were investigated in relation to the effect on the CNTs formation from plastics waste, temperature and metal loading content. When the effect of $\mathrm{Ni}$ content $\left(0.1\right.$ and $\left.1.0 \mathrm{molL}^{-1}\right)$ was studied, thermochemical conversion of waste HDPE was investigated at $800{ }^{\circ} \mathrm{C}$. When the effect of reaction temperature $\left(600,700\right.$, and $\left.800{ }^{\circ} \mathrm{C}\right)$ was studied, the $1.0 /$ sphere catalyst was used. CNTs formation from thermochemical conversion of plastics waste was investigated according to both quantitative analysis and qualitative analysis. The quantitative analysis of CNTs was further discussed based on amount of amorphous and filamentous carbons obtained from TGA-TPO analysis of the spent catalysts. And the quality of CNTs production is analysed and discussed mainly based on SEM and TEM results.

\subsubsection{Influence of reaction temperature}

Original sphere substrate without Ni loading was studied by XRD, SEM and TEM analysis. Sphere substrate was identified as $\mathrm{Al}_{2} \mathrm{O}_{3}$ by XRD analysis (Figure 2), and consist of 44.1 wt.\% Al element and 55.9 wt.\% O element, respectively (EDX analysis). Figure 3(A) shows a simulated sphere substrate with regular sphere shape and about $0.75 \mathrm{~mm}$ radius. SEM results (Figure 3(B)) further demonstrate the shape and diameters of sphere substrate. It is solid inside of the sphere (cross-section image shown in Figure 3(C)) and $\mathrm{Al}_{2} \mathrm{O}_{3}$ with short fibre structure (Figure 3(D)) was clearly showed in TEM result. 


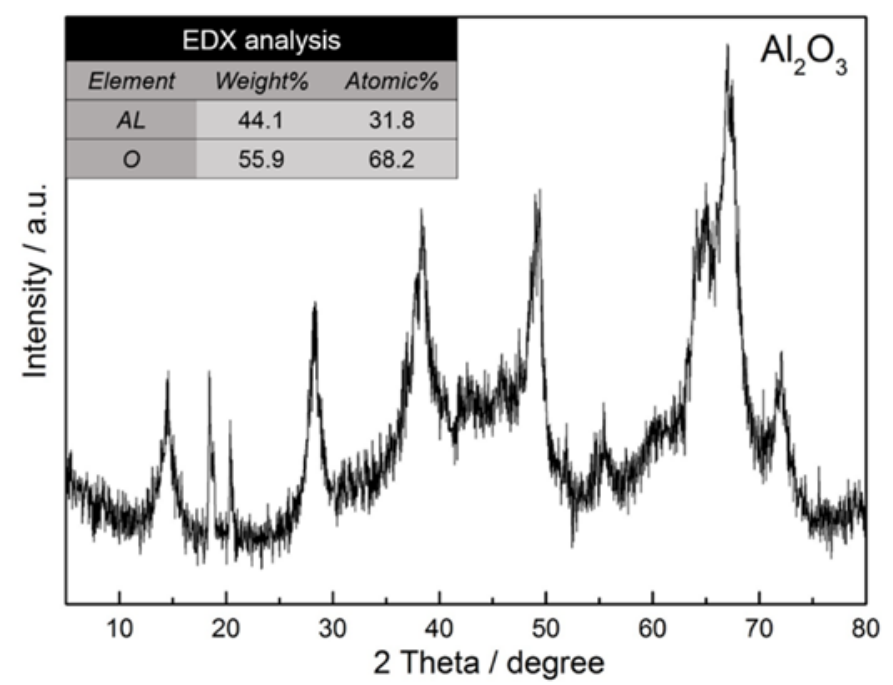

Figure 2. XRD and EDX-TEM analysis for original fresh $\mathrm{Ni} /$ sphere catalysts without Ni loading

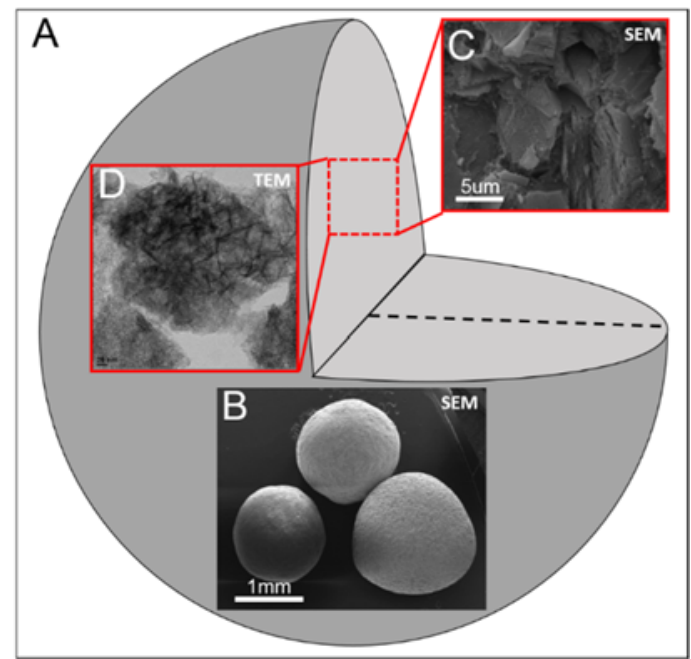

Figure 3. Original sphere structure: (A) simulated spherical structure of substrate; (B) SEM image of spherical alumina; (C) SEM image of the cross-section of sphere alumina; (D) TEM image of sphere alumina.

At present, the widely accepted CNTs growth mechanism can be described in Figure 4 (Yellampalli, 2011). There are two general mechanisms according to the interaction between catalysts and substrate, tip-growth model (Figure 4(B)) and base-growth model (Figure $4(C)$ ). When the catalyst-substrate interaction is weak, hydrocarbon decomposes on the top surface of the catalyst metal, carbon diffuses through catalytic 
particles. And CNTs are formed across the bottom of metal particles, pushing the catalyst particle off the substrate. The CNTs growth process continues until the catalytic activity ceases. For the base-growth model, when the catalyst-substrate interaction is strong, initial hydrocarbon decomposition and carbon diffusion take place similar to that in the tip-growth model, but the catalyst particles remain at the bottom of the substrate.

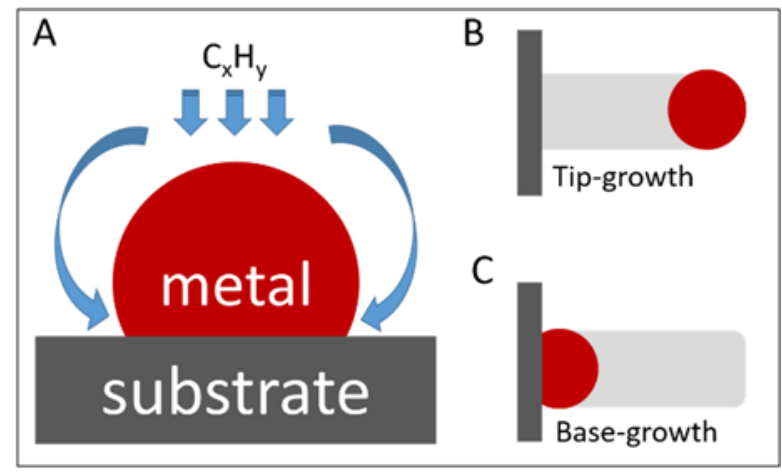

Figure 4. Schematic representation of CNTs growth mechanism.

Based on this CNTs growth mechanism, CNTs growth and synthesis on $\mathrm{Al}_{2} \mathrm{O}_{3}$ sphere substrate from waste plastics was investigated with the help of TEM and SEM analysis. Figure 5 presents the TEM images of the fresh 0.1 /sphere and 1.0/sphere catalysts. Metal particles on the surface of the alumina sphere can be clearly observed. CNTs were synthesised under three different temperatures including $600{ }^{\circ} \mathrm{C}, 700{ }^{\circ} \mathrm{C}$ and $800^{\circ} \mathrm{C}$. The produced CNTs on the surface of the catalyst were studied using SEM on both cross-section and the surface of the spent sphere catalysts (Figure 6). It is noted that the produced filamentous carbons are assumed to be CNTs which were confirmed by TEM analysis. At $600{ }^{\circ} \mathrm{C}$, small amount of CNTs could be observed on the surface or inside (cross-section) of the spent catalysts. With the increase of temperature to $700{ }^{\circ} \mathrm{C}$, some short and disordered amorphous CNTs are observed on the surface of sphere. However, inside the catalysts (cross section SEM analysis), CNTs are not observed. With the further increase of catalytic reaction temperature to $800{ }^{\circ} \mathrm{C}$, many filamentous CNTs are observed on the surface of the spent catalysts. However CNTs could still not be found from the cross-section of the spent catalysts. 
According to the SEM analysis of the spent catalysts used at three different temperatures, the growth of CNTs could not happen inside the spent alumina spherebased catalysts. Therefore, the CNTs growth mechanism is proposed in Figure 6 (A) and (B). Metal particles were loaded on the surface of sphere, the Ni-liquid couldn't permeate inside the sphere by this co-precipitation method, therefore, there was no CNTs gown inside of spent catalysts. This is consistent with early research reported by Nahil et al.(Nahil et al., 2015). The Ni-based catalysts with poorest porosity structures resulted in the highest CNTs yield, which indicating that the CNTs formation mainly occurs on the surface of catalysts.
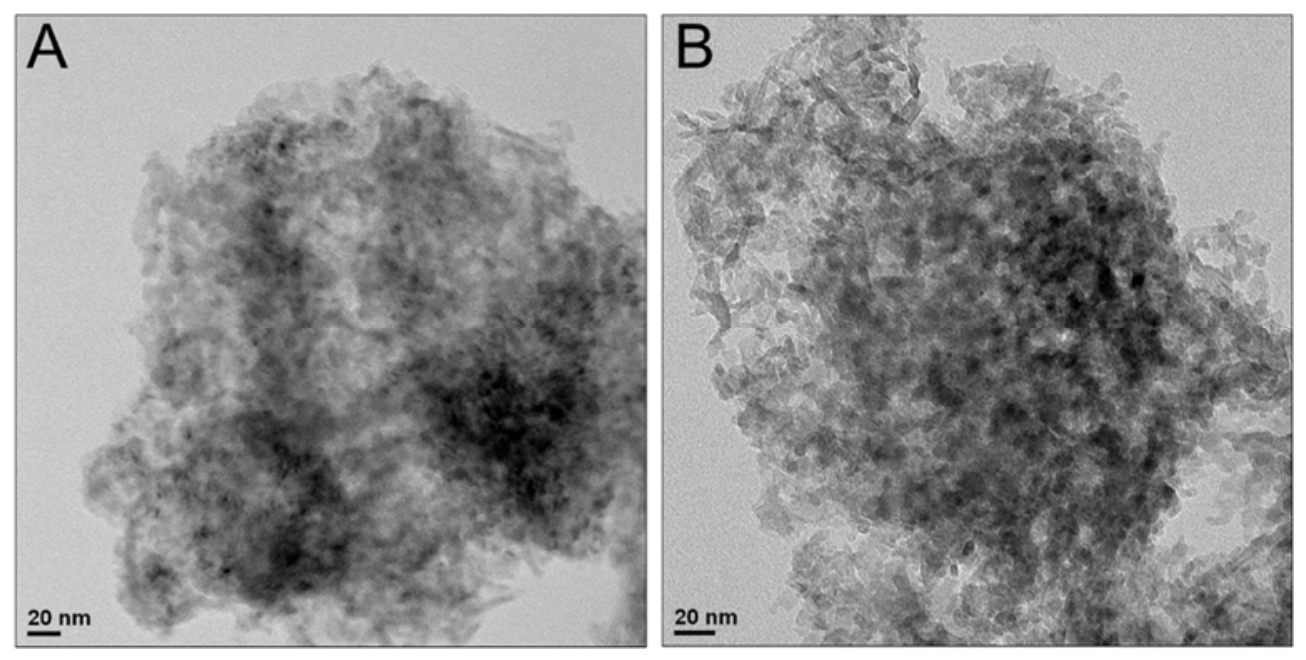

Figure 5. TEM results for (A) 0.1 and (B) 1.0 fresh Ni/sphere catalysts 


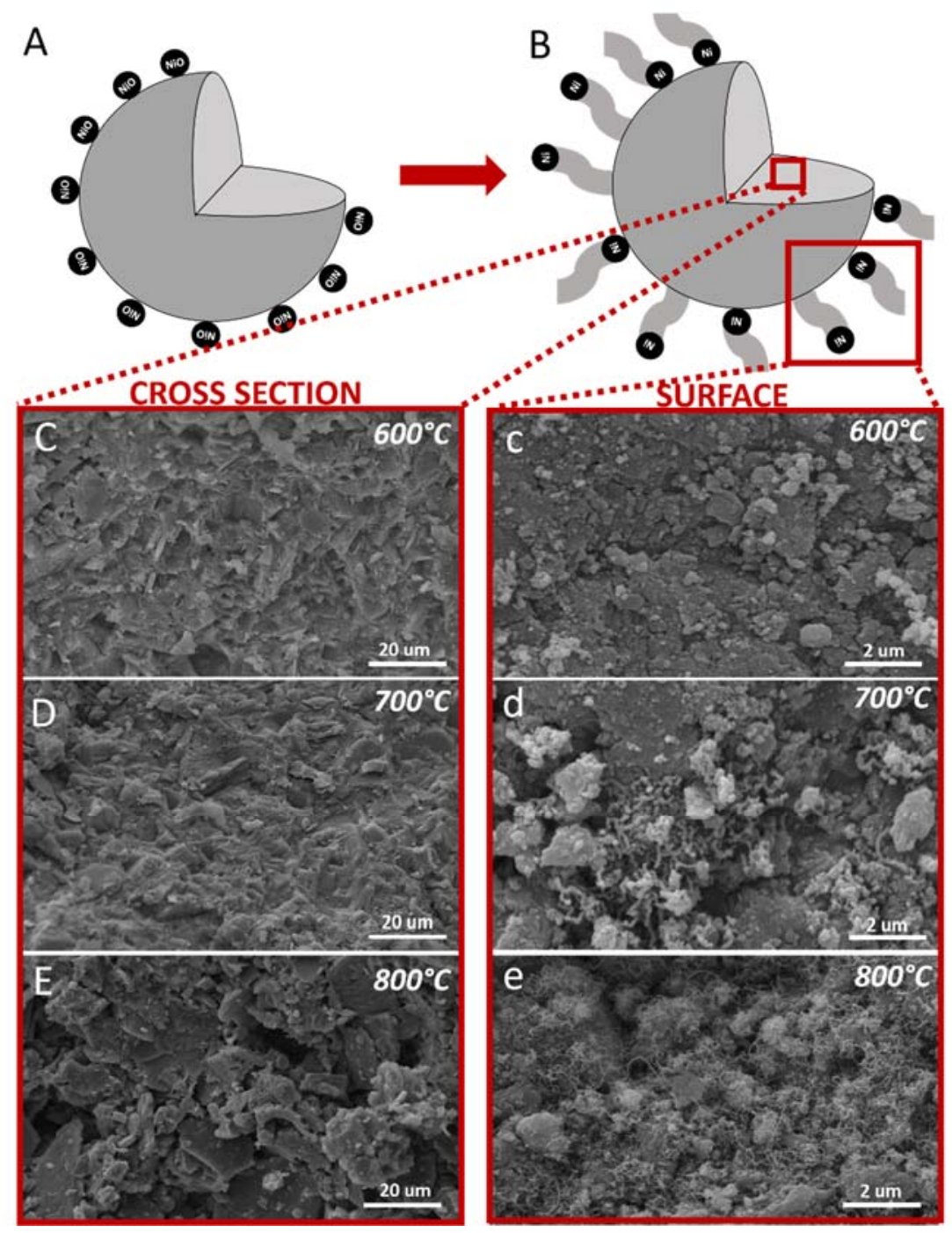

Figure 6. SEM results of the cross-section and surfaces of the reacted Ni/sphere catalysts at three different temperatures $\left(600{ }^{\circ} \mathrm{C}, 700{ }^{\circ} \mathrm{C}, 800{ }^{\circ} \mathrm{C}\right)$.

The effect of reaction temperature on the growth of CNTs through thermal conversion from HDPE is studied using Ni/sphere catalysts. Three different reaction temperatures $\left(600{ }^{\circ} \mathrm{C}, 700{ }^{\circ} \mathrm{C}\right.$ and $\left.800{ }^{\circ} \mathrm{C}\right)$ were investigated using the $1.0 /$ sphere catalyst. Scanning electron microscope (SEM), and temperature program oxidation (TGA-TPO and DTGTPO) analysis were carried out to the spent catalysts. SEM results (Figure 6) reveals that CNTs cannot grow at $600{ }^{\circ} \mathrm{C}$. CNTs are observed between $700{ }^{\circ} \mathrm{C}$ and $800{ }^{\circ} \mathrm{C}$ with different structure and yield. At $600{ }^{\circ} \mathrm{C}$, no CNTs can be observed from SEM image; most of the deposited materials were carbonaceous or amorphous carbon, which extensionally proved by TPO analysis. At $700{ }^{\circ} \mathrm{C}$, small amount of CNTs mixed with 
amorphous carbons are observed. Increasing the temperature to $800{ }^{\circ} \mathrm{C}$ results in the formation of many carbon nanotubes with aligned and uniform diameter. This observation is further supported by TPO analysis (Figure 7). At reaction temperature of $600{ }^{\circ} \mathrm{C}$, the oxidation of carbons only happens below $550{ }^{\circ} \mathrm{C}$ indicating the absence of CNTs which are normally oxidised above $550^{\circ} \mathrm{C}$. For amorphous carbons (oxidation temperature below $550{ }^{\circ} \mathrm{C}$ ), the yield was decreased from 1.2 to $1.0 \mathrm{wt} . \%$, when the temperature is increased from $700{ }^{\circ} \mathrm{C}$ to $800{ }^{\circ} \mathrm{C}$. This result is consistent with the SEM analysis (Figure 6), where amorphous carbons could be clearly observed on the spent catalyst tested at $700{ }^{\circ} \mathrm{C}$. Furthermore, the formation of CNTs is increased from 1.0 wt. $\%$ and 7.5 wt. $\%$ when the reaction temperature was increased $700{ }^{\circ} \mathrm{C}$ and $800{ }^{\circ} \mathrm{C}$. DTG-TPO results show that the oxidation peak moved to higher temperature with the increase of experimental temperature from $600^{\circ} \mathrm{C}$ and $800^{\circ} \mathrm{C}$, indicating that the CNTs might be more crystalized at $800{ }^{\circ} \mathrm{C}$ reaction temperature.

The results suggest that the quantity and quality of CNTs are improved with increasing temperature using the $\mathrm{Ni} /$ sphere catalysts. This is also consistent with other research on the effected of temperature on CNTs formation. For example, Acomb et al. (Acomb et al., 2015) reported the effect of growth temperature $\left(700^{\circ} \mathrm{C}, 800{ }^{\circ} \mathrm{C}\right.$, and $\left.900{ }^{\circ} \mathrm{C}\right)$ on the CNTs production using low density polyethylene (LDPE) with $\mathrm{Fe} / \mathrm{Al}_{2} \mathrm{O}_{3}$ as catalyst. They reported that a higher temperature generated a higher fraction of CNTs formation. Also, Hornyak et al. (Hornyak et al., 1999), who investigated the CNTs formation with Co-based catalysts from propylene gas, found that amorphous carbons were formed at around $550{ }^{\circ} \mathrm{C}$, while CNTs were formed at temperature higher than $800{ }^{\circ} \mathrm{C}$.

CNTs are formed by hydrocarbon atom dissolving, diffusion and precipitating through the catalyst in CVD process, and the rates of these three steps are affected by both temperature and the concentration of carbon atoms (MUATAZ et al., 2006). Higher temperature seems to produce well crystallized, uniform, less defective nanotube with high yield and purity. The effect of reaction temperature on CNTs synthesis by CVD is mainly related to carbon source and catalytic activity. In this study, higher reaction temperature promotes the decomposition of HDPE to increase the concentration of 
carbon atoms, which could increase the growth rate of CNTs formation. And the dissolving and diffusing rates of carbon atoms could also be increased with the increase of reaction temperature. The research from $\mathrm{Wu}$ and Williams (Wu and Williams, 2010) supports this, they reported that more reactive carbon sources were produced from pyrolysis of waste plastics at higher temperature. Lee et al. (Lee et al., 2001) also reported higher temperature promoted the diffusion and reaction rates of carbons, resulting in the enhanced formation of CNTs. Therefore, in this study, less amorphous carbons and more CNTs were formed at $800{ }^{\circ} \mathrm{C}$ compared to $600{ }^{\circ} \mathrm{C}$. In addition, the reaction temperature could also affect the catalytic conversion of hydrocarbons derived from pyrolysis of plastics. For example, Mishra et al. (Mishra et al., 2012) synthesized MWCNTs at three different temperatures $\left(600^{\circ} \mathrm{C}, 700^{\circ} \mathrm{C}\right.$, and $\left.800^{\circ} \mathrm{C}\right)$ from pyrolytic degradation of PP with Ni catalysts; they found the increase of temperature resulted in the decrease of amorphous carbons and the increase of CNTs purity. Therefore, $800{ }^{\circ} \mathrm{C}$ was assumed as the optimum temperature for this study.
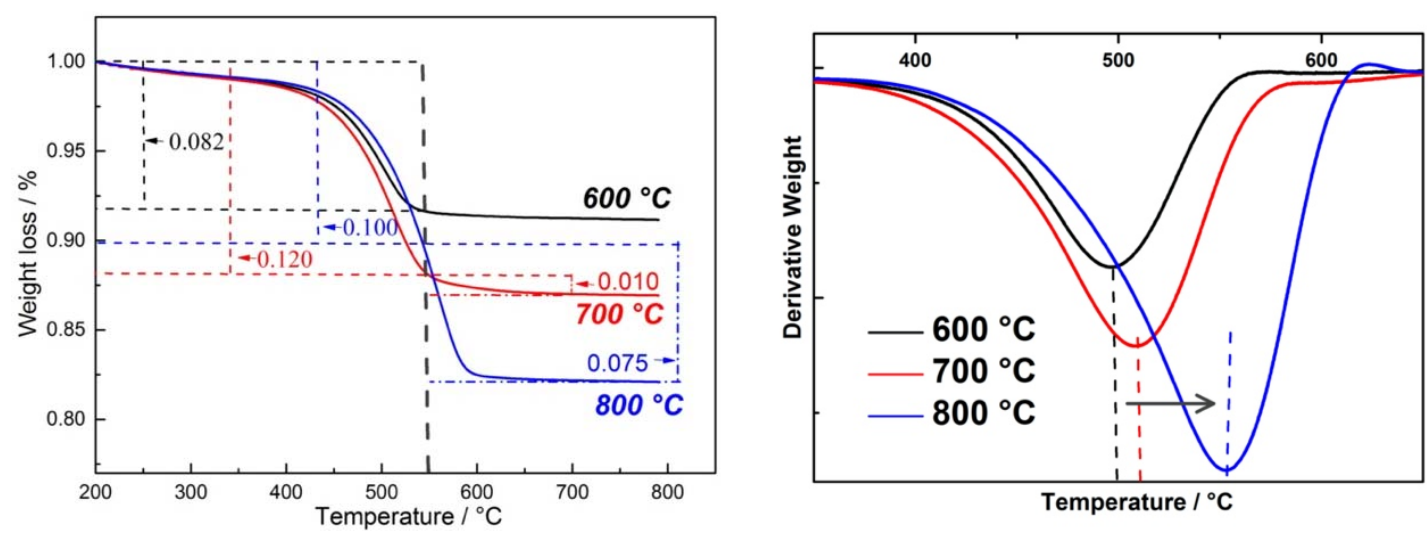

Figure 7. TPO results and corresponding DTG results of the spent 1.0/sphere catalysts at $600{ }^{\circ} \mathrm{C}, 700{ }^{\circ} \mathrm{C}$, and $800{ }^{\circ} \mathrm{C}$.

\subsubsection{Influence of nickel loading}

Thermochemical conversion of waste HDPE was investigated in the presence of $\mathrm{Ni} /$ sphere catalysts with different $\mathrm{Ni}$ contents at $800^{\circ} \mathrm{C}$. Figure $8(\mathrm{~A})$ and (B) show the SEM results and corresponding TEM results for the produced filamentous carbons. 
Large amount of filaments carbons are observed on the surface of the spent 0.1 and 1.0/sphere catalysts. TEM results further prove that the filaments carbons are mostly CNTs. Using SEM images, it is difficult to distinguish the quantity and quality between the 0.1 and 1.0/sphere catalysts. For qualitative comparison, the average diameters of CNTs with standard deviation (Figure 8(a) and (b)) were analysed and discussed according to the SEM results using Image J, representative. The standard deviation (SD) number can be used as a main factor to identify the quality of CNTs formation; a better quality of CNTs is identified with a smaller SD number (Liu et al., 2018). It could be noticed that the diameter of CNTs is slightly increased with an increase of Ni content. The 0.1 /sphere catalyst produce CNTs with a diameter of $40.2 \pm 8.6 \mathrm{~nm}$, and the $1.0 /$ sphere catalyst result in CNTs with a larger diameter of $55.2 \pm 7.9 \mathrm{~nm}$. It is reported that an increase of metal content led to an increase metal particle sizes (Jiang et al., 2016)(Chen et al., 2005). For example, Daudouin et al. increased the Ni loading from 1.0 to $18.5 \mathrm{wt} . \%$ to increase the catalytic particle sizes from 1.6 to $7.3 \mathrm{~nm}$ (Baudouin et al., 2013). In addition, the diameter of CNTs produced from hydrocarbon deposition have almost the same diameter with catalytic metal particles, due to CNTs are diffused by catalytic metal particles during growth process (Figure 4). Therefore, the size of metal particles determine the diameter of filamentous carbons (Sinnott et al., 1999). In this work, the average diameter of CNTs is increased from 40.2 to $55.2 \mathrm{~nm}$, as an increase of Ni loading from 0.1 to $1.0 \mathrm{mlL}^{-1}$. Similar results were also found by other researchers (Baker and Waite, 1975; Cheung et al., 2002; Da Silva et al., 2014; Danafar et al., 2009; Gorbunov et al., 2002; Lastoskie et al., 1993; Li et al., 2001; Sinnott et al., 1999). Sinnott et al. (Sinnott et al., 1999) studied the effect of Fe content on the diameter of CNTs produced from ferrocene-xylene mixture through CVD. They reported that the average Fe particle size was decreased from 35.3 to $28.2 \mathrm{~nm}$ with a decrease of Fe content from 0.75 to 0.075 at\%. Cheung et al. (Cheung et al., 2002) used Fe-based catalysts with average diameters of 3, 9, and $13 \mathrm{~nm}$ to synthesize CNTs from ethylene with average diameters of 3, 7, and $12 \mathrm{~nm}$, respectively. The standard deviation decreased from $8.6 \mathrm{~nm}$ to $7.9 \mathrm{~nm}$ with the increase of $\mathrm{Ni}$ loading indicated the improved 
quality of CNTs. This might related to the enhanced thermal stability and graphitization degree by Ni species as reported by Yao et al.(Yao et al., 2017).

The quantitative analysis on the amount of amorphous carbon productions was obtained by TGA-TPO analysis (Figure 9). It is assumed that the oxidation temperature below $550{ }^{\circ} \mathrm{C}$ is assigned to amorphous carbons and the oxidation above $550{ }^{\circ} \mathrm{C}$ in $\mathrm{TPO}$ is assigned to filamentous carbons (confirmed CNTs in TEM) (Wu et al., 2017). Two different types of carbons separated and analysed by vertical black imaginary line (Figure 9). The total carbon yield could be represented by $\mathrm{Y}$ axis 'the weight loss' of catalyst in relation to the initial catalyst weight. According to TPO analysis of the spent catalysts with different Ni loadings, the formation of amorphous carbons (about $1.0 \%$ ) is the same for the 0.1 and 1.0 /sphere catalysts, and the production of CNTs production is increased from 6.2 to $7.5 \mathrm{wt} . \%$, when the catalyst is changed from the $0.1 /$ sphere to the 1.0 /sphere catalyst. Therefore, the 1.0 /sphere catalyst is a better candidate for CNTs production in this work.
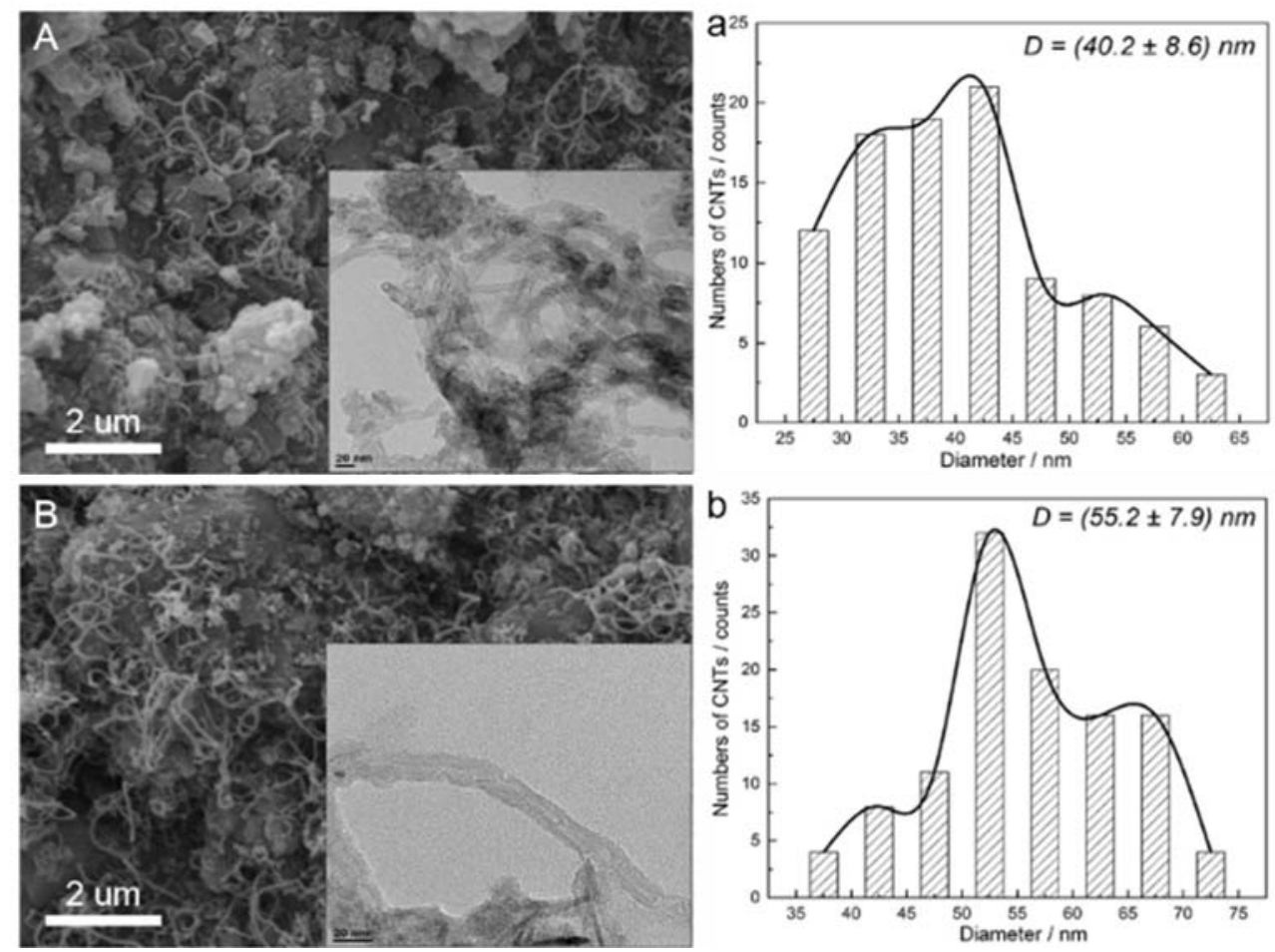
Figure 8. SEM, TEM results and diameter distribution CNTs for (A) 0.1 spent

$\mathrm{Ni} /$ sphere catalyst and (B) 1.0 spent $\mathrm{Ni} /$ sphere catalyst.
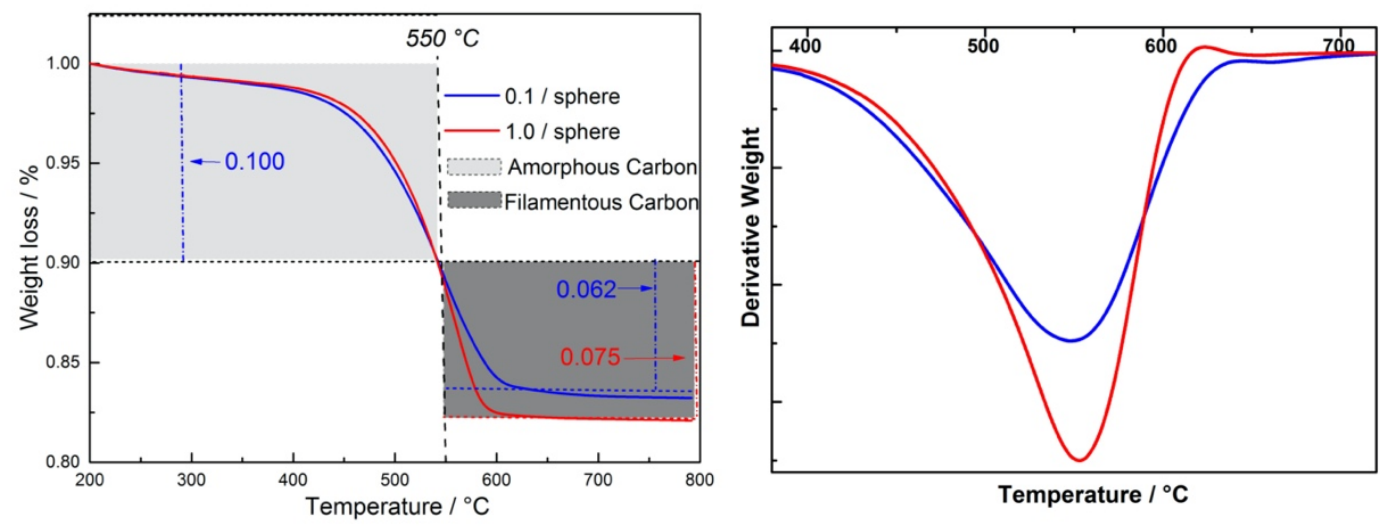

Figure 9. DTG-TPO and DSC results of the spent 0.1 and $1.0 /$ ceramic at $800{ }^{\circ} \mathrm{C}$

\section{Conclusion}

Carbon nanotubes produced from waste plastics using nickel based sphere catalysts have been studied. The formation of CNTs only occurs on the surface of catalyst. In addition, the carbon nanotubes formation conditions including metal loading and reaction temperature have been optimized from catalytic thermo-chemical conversion of waste plastics using nickel sphere catalysts. An optimum temperature $800{ }^{\circ} \mathrm{C}$ is suggested for the production of CNTs. An increase of Ni content on alumina sphere results in an increase of the diameter of CNTs. In addition, a higher Ni loading produces a higher yield of CNTs.

\section{Acknowledgement}

This project has received funding from the European Union's Horizon 2020 research and innovation programme under the Marie Skłodowska-Curie grant agreement No 823745.

\section{References}


Acomb, J.C., Wu, C., Williams, P.T., 2016. The use of different metal catalysts for the simultaneous production of carbon nanotubes and hydrogen from pyrolysis of plastic feedstocks. Appl. Catal. B Environ. 180, 497-510. https://doi.org/10.1016/j.apcatb.2015.06.054

Acomb, J.C., Wu, C., Williams, P.T., 2015. Effect of growth temperature and feedstock:catalyst ratio on the production of carbon nanotubes and hydrogen from the pyrolysis of waste plastics. J. Anal. Appl. Pyrolysis 113, 231-238. https://doi.org/10.1016/j.jaap.2015.01.012

Ago, H., Uehara, N., Yoshihara, N., Tsuji, M., Yumura, M., Tomonaga, N., Setoguchi, T., 2006. Gas analysis of the CVD process for high yield growth of carbon nanotubes over metal$\begin{array}{llllll}\text { supported } & \text { catalysts. } & \text { Carbon } & \text { N. }\end{array}$ https://doi.org/10.1016/j.carbon.2006.05.049

Baker, R.T.K., Waite, R.J., 1975. Formation of carbonaceous deposits from the platinum-iron catalyzed decomposition of acetylene. J. Catal. 37, 101-105. https://doi.org/10.1016/00219517(75)90137-2

Baudouin, D., Rodemerck, U., Krumeich, F., Mallmann, A. De, Szeto, K.C., Ménard, H., Veyre, L., Candy, J.P., Webb, P.B., Thieuleux, C., Copéret, C., 2013. Particle size effect in the low temperature reforming of methane by carbon dioxide on silica-supported Ni nanoparticles. J. Catal. 297, 27-34. https://doi.org/10.1016/j.jcat.2012.09.011

Chen, D., Christensen, K.O., Ochoa-Fernández, E., Yu, Z., Tøtdal, B., Latorre, N., Monzón, A., Holmen, A., 2005. Synthesis of carbon nanofibers: Effects of Ni crystal size during methane decomposition. J. Catal. 229, 82-96. https://doi.org/10.1016/j.jcat.2004.10.017

Cheung, C.L., Kurtz, A., Park, H., Lieber, C.M., 2002. Diameter-controlled synthesis of carbon nanotubes. J. Phys. Chem. B 106, 2429-2433. https://doi.org/10.1021/jp0142278

Da Silva, A.L.M., Den Breejen, J.P., Mattos, L. V., Bitter, J.H., De Jong, K.P., Noronha, F.B., 2014. Cobalt particle size effects on catalytic performance for ethanol steam reforming -Smaller is better. J. Catal. 318, 67-74. https://doi.org/10.1016/j.jcat.2014.07.020 
Danafar, F., Fakhru'I-Razi, A., Salleh, M.A.M., Biak, D.R.A., 2009. Fluidized bed catalytic chemical vapor deposition synthesis of carbon nanotubes-A review. Chem. Eng. J. 155, 37-48. https://doi.org/10.1016/j.cej.2009.07.052

Dasgupta, K., Joshi, J.B., Banerjee, S., 2011. Fluidized bed synthesis of carbon nanotubes - A review. Chem. Eng. J. 171, 841-869. https://doi.org/10.1016/j.cej.2011.05.038

Dichiara, A., Bai, J., 2012. The growth of carbon nanotube multilayers on ceramic $\mu$-particles by catalytic chemical vapour deposition. Diam. Relat. Mater. 29, 52-58. https://doi.org/10.1016/j.diamond.2012.07.010

Fajardo, H.V., Probst, L.F.D., 2006. Production of hydrogen by steam reforming of ethanol over Ni/Al2O3 spherical catalysts. Appl. Catal. A Gen. 306, 134-141. https://doi.org/10.1016/j.apcata.2006.03.043

Gorbunov, A., Jost, O., Pompe, W., Graff, A., 2002. Role of the catalyst particle size in the synthesis of single-wall carbon nanotubes. Appl. Surf. Sci. 197-198, 563-567. https://doi.org/10.1016/S0169-4332(02)00335-5

Gou, X., Zhao, D., Wu, C., 2020. Catalytic conversion of hard plastics to valuable carbon nanotubes. J. Anal. Appl. Pyrolysis 145, 104748. https://doi.org/10.1016/j.jaap.2019.104748 Han, I.T., Kim, B.K., Kim, H.J., Yang, M., Jin, Y.W., Jung, S.J., Lee, N., Kim, S.K., Kim, J.M., 2004. Effect of Al and catalyst thicknesses on the growth of carbon nanotubes and application to gated field emitter arrays. Chem. Phys. Lett. 400, 139-144. https://doi.org/10.1016/j.cplett.2004.10.123

He, D., Bozlar, M., Genestoux, M., Bai, J., 2010. Diameter- and length-dependent selforganizations of multi-walled carbon nanotubes on spherical alumina microparticles. Carbon N. Y. 48, 1159-1170. https://doi.org/10.1016/j.carbon.2009.11.039

He, D., Li, H., Li, W., Haghi-Ashtiani, P., Lejay, P., Bai, J., 2011. Growth of carbon nanotubes in six orthogonal directions on spherical alumina microparticles. Carbon N. Y. 49, 2273-2286. https://doi.org/10.1016/j.carbon.2011.01.060 
Hornyak, G.L., Dillon, A.C., Parilla, P.A., Schneider, J.J., Czap, N., Jones, K.M., Fasoon, F.S., Mason, A., Heben, M.J., 1999. Template synthesis of carbon nanotubes. Nanostructured Mater. 12, 83-88. https://doi.org/10.1016/S0965-9773(99)00071-9

lijima, S., 1991. Helical microtubules of graphitic carbon. Nature 354, 56-58. https://doi.org/https://doi.org/10.1038/354056a0

Jiang, B., Zhang, C., Wang, K., Dou, B., Song, Y., Chen, H., Xu, Y., 2016. Highly dispersed $\mathrm{Ni} /$ montmorillonite catalyst for glycerol steam reforming: Effect of $\mathrm{Ni}$ loading and calcination temperature. Appl. Therm. Eng. 109, 99-108. https://doi.org/10.1016/j.applthermaleng.2016.08.041

Kiadehi, A.D., Taghizadeh, M., 2018. Evaluation of a micro-channel reactor for steam reforming of ethylene glycol: A comparative study of catalytic activity of Pt or/and Ni supported T-alumina catalysts. Int. J. Hydrogen Energy 43, 4826-4838. https://doi.org/10.1016/j.ijhydene.2018.01.103

Lastoskie, C., Gubbins, K.E., Quirke, N., 1993. Pore size distribution analysis of microporous carbons: A density functional theory approach. J. Phys. Chem. 97, 4786-4796. https://doi.org/10.1021/j100120a035

Lee, C.J., Park, J., Huh, Y., Yong Lee, J., 2001. Temperature effect on the growth of carbon nanotubes using thermal chemical vapor deposition. Chem. Phys. Lett. 343, 33-38. https://doi.org/10.1016/S0009-2614(01)00680-7

Lee, T.Y., Han, J.H., Choi, S.H., Yoo, J.B., Park, C.Y., Jung, T., Yu, S.G., Lee, J., Yi, W., Kim, J.M., 2003. Comparison of source gases and catalyst metals for growth of carbon nanotube. Surf. Coatings Technol. 169-170, 348-352. https://doi.org/10.1016/S0257-8972(03)00108-7

Li, Q., Yan, H., Zhang, J., Liu, Z., 2004. Effect of hydrocarbons precursors on the formation of carbon nanotubes in chemical vapor deposition. Carbon N. Y. 42, 829-835. https://doi.org/10.1016/j.carbon.2004.01.070 
Li, Y., Kim, W., Zhang, Y., Rolandi, M., Wang, D., Dai, H., 2001. Growth of single-walled carbon nanotubes from discrete catalytic nanoparticles of various sizes. J. Phys. Chem. B 105, 1142411431. https://doi.org/10.1021/jp012085b

Lindström, B., Pettersson, L.J., Menon, G., 2002. Activity and characterization of $\mathrm{Cu} / \mathrm{Zn}, \mathrm{Cu} / \mathrm{Cr}$ and $\mathrm{Cu} / \mathrm{Zr}$ on $\mathrm{\gamma}$-alumina for methanol reforming for fuel cell vehicles. Appl. Catal. A Gen. 234, 111-125. https://doi.org/10.1016/S0926-860X(02)00202-8

Liu, X., Sun, H., Wu, C., Patel, D., Huang, J., 2018. Thermal Chemical Conversion of High-Density Polyethylene for the Production of Valuable Carbon Nanotubes Using Ni/AAO Membrane Catalyst. Energy and Fuels 32, 4511-4520. https://doi.org/10.1021/acs.energyfuels. $7 b 03160$ Mishra, N., Das, G., Ansaldo, A., Genovese, A., Malerba, M., Povia, M., Ricci, D., Di Fabrizio, E., Di Zitti, E., Sharon, Madhuri, Sharon, Maheshwar, 2012. Pyrolysis of waste polypropylene for the synthesis of carbon nanotubes. J. Anal. Appl. Pyrolysis 94, 91-98. https://doi.org/10.1016/j.jaap.2011.11.012

MUATAZ, A.A., AHMADUN, F., GUAN, C., MAHDI, E., RINALDI, A., 2006. Effect of Reaction Temperature on the Production of Carbon Nanotubes. Nano 01, 251-257. https://doi.org/10.1142/s1793292006000288

Nahil, M.A., Wu, C., Williams, P.T., 2015. Influence of metal addition to Ni-based catalysts for the co-production of carbon nanotubes and hydrogen from the thermal processing of waste polypropylene. Fuel Process. Technol. 130, 46-53. https://doi.org/10.1016/j.fuproc.2014.09.022

Radushkevich, L. V, Lukyanovich, V. áM, 1952. O strukture ugleroda, obrazujucegosja pri termiceskom razlozenii okisi ugleroda na zeleznom kontakte. Zurn Fis. Chim 26, 88-95.

Sinnott, S.B., Andrews, R., Qian, D., Rao, A.M., Mao, Z., Dickey, E.C., Derbyshire, F., 1999. Model of carbon nanotube growth through chemical vapor deposition. Chem. Phys. Lett. 315, 25-30. https://doi.org/10.1016/S0009-2614(99)01216-6 
Trojanowicz, M., 2006. Analytical applications of carbon nanotubes: a review. TrAC - Trends Anal. Chem. 25, 480-489. https://doi.org/10.1016/j.trac.2005.11.008

Wu, C., Nahil, M.A., Miskolczi, N., Huang, J., Williams, P.T., Engineering, P., Ls, L., 2017. Production and application of carbon nanotubes, as a co-product of hydrogen from the pyrolysis-catalytic reforming of waste plastic. Process Saf. Environ. Prot. 103, 107-114. https://doi.org/10.1016/j.psep.2016.07.001

Wu, C., Williams, P.T., 2010. Pyrolysis-gasification of post-consumer municipal solid plastic waste for hydrogen production. Int. J. Hydrogen Energy 35, 949-957. https://doi.org/10.1016/j.ijhydene.2009.11.045

Yao, D., Wang, C.H., 2020. Pyrolysis and in-line catalytic decomposition of polypropylene to carbon nanomaterials and hydrogen over Fe- and Ni-based catalysts. Appl. Energy 265, 114819. https://doi.org/10.1016/j.apenergy.2020.114819

Yao, D., Wu, C., Yang, H., Zhang, Y., Nahil, M.A., Chen, Y., Williams, P.T., Chen, H., 2017. Coproduction of hydrogen and carbon nanotubes from catalytic pyrolysis of waste plastics on NiFe bimetallic catalyst. Energy Convers. Manag. 148, 692-700. https://doi.org/10.1016/j.enconman.2017.06.012

Yellampalli, S., 2011. Carbon Nanotubes: Synthesis, Characterization, Applications. BoD-Books on Demand.

Zhuo, C., Levendis, Y.A., 2014. Upcycling waste plastics into carbon nanomaterials: A review. J. Appl. Polym. Sci. 131, 1-14. https://doi.org/10.1002/app.39931 